\title{
Por norma ler as normas
}

\author{
Catarina Empis*
}

«Melhorar é mudar; ser-se perfeito é mudar muitas vezes»

Winston Churchill

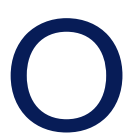
processo de apreciação/revisão dos artigos submetidos à Revista Portuguesa de Clínica Geral (RPCG) é complexo, como o de qualquer revista com revisão inter-pares, mas pode ser muito enriquecedor para ambas as partes: quem escreve/submete e quem lê/revê/aprecia.

Os autores aprendem ao terem outros olhos, sem o peso da emotividade com que, desejavelmente, se envolvem nos seus próprios trabalhos, a olhá-los de outra forma e a colher sugestões para a sua melhoria. Os editores e revisores aprendem na confrontação com novos conteúdos e novas formas de olhar e abordar novas e velhas questões.

Na apreciação dos artigos submetidos, no que respeita ao conteúdo, a originalidade é um ingrediente bem apetecível. Já na forma não há grande lugar à inovação. Há que seguir preceitos. É nesse âmbito que surgem as Normas de Publicação na Revista Portuguesa de Clínica Geral. ${ }^{1}$ Só cumprindo regras seremos capazes de atingir a necessária clareza e uniformidade na comunicação tornando fácil e agradável a leitura da nossa revista.

O Conselho Editorial tem-se preocupado em tornar todo o circuito editorial transparente e em melhorá-lo de forma a torná-lo mais ágil e a minimizar os erros.

Nesse sentido, têm sido implementados vários processos de regulação para clarificar as normas e aumentar o seu cumprimento, como a criação de uma lista de verificação para os autores preencherem antes da submissão do artigo.

Do lado do circuito editorial, para evitar que as questões formais se perdessem ante a preocupação com o aperfeiçoamento do conteúdo, foi criada recentemente uma nova etapa no circuito dos artigos submetidos, que precede todas as que já existiam e que visa exclu-

*Editora da Revista Portuguesa de Clínica Geral. sivamente a verificação do cumprimento das normas de publicação. Em média tem havido necessidade de duas reformulações dos artigos até ficarem de acordo com as normas de publicação o que acarreta um atraso, nalguns casos considerável, na passagem à fase seguinte do circuito editorial: a análise daquilo que é de facto único de cada artigo, o seu conteúdo.

Internamente, já temos reflectido sobre os aspectos que mais frequentemente falham no cumprimento das normas de submissão de artigos à RPCG e tentaremos salientá-los e clarificá-los na próxima revisão das normas. Mas esse esforço só será recompensado se houver uma preocupação dos autores em esmiuçar as normas.

Eis os erros mais comuns que têm sido detectados no processo de validação pré-editorial da revista. Ao citá-los, esperamos que sejam tomados em consideração por todos quantos desejem publicar na nossa revista:

- Devem estar explícitos no documento os dados do autor responsável pela correspondência com a revista acerca do manuscrito e do autor a quem deve ser dirigida a correspondência sobre o artigo após a sua publicação na revista. Se os dados forem sobreponíveis esse facto deve ser mencionado. ${ }^{1}$

- Todos os artigos devem conter título, resumo e palavras-chave em inglês. ${ }^{1}$

- As palavras-chave em português devem corresponder, sempre que existirem, a descritores em ciências da saúde ${ }^{2}$ e, em inglês, a termos da lista de descritores médicos MeSH. ${ }^{1,3}$

- Os artigos devem conter referências bibliográficas (e não bibliografia) as quais deverão seguir as normas de Vancouver. ${ }^{4}$ Os números das referências bibliográficas não devem constar no texto entre parêntesis e devem ser colocados após a pontuação. ${ }^{1}$

- A seguir às referências bibliográficas, deve constar texto que os autores queiram publicar declarando a presença ou ausência de conflitos de interesses e financiamento do estudo. ${ }^{1}$

- As páginas que se seguem à declaração de conflito de interesses e financiamento do estudo devem in- 
cluir as ilustrações enviadas, cada uma em sua folha, com indicação do respectivo número e legenda e não pode ser ultrapassado o número máximo de ilustrações permitido para a tipologia de artigo escolhida. ${ }^{1}$

- Quando das ilustrações fizerem parte fotografias, deve ser apresentado consentimento informado assinado pelos doentes fotografados. ${ }^{1}$

- Quando as ilustrações se tratarem de figuras ou quadros não originais deve ser enviada a autorização para publicação, de acordo com as normas de Van-

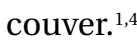

- O resumo (com um máximo de 300 palavras) deve ser, obrigatoriamente, estruturado nos subcapítulos definidos nas normas para a respectiva tipologia de artigo, mantendo-se a designação tal e qual como nelas figura, nomeadamente no que respeita ao número (singular $v$ s plural). ${ }^{1}$ Para além disso, de forma a uniformizar a nomenclatura entre os artigos publicados na RPCG, a terminologia preferida em inglês é: acknowledgments (para agradecimentos), conclusions (para conclusões), discussion (para discussão), data sources (para fontes de dados), introduction (para introdução), setting (para local), methods (para métodos), review methods (para métodos de revisão), objectives (para objectivos), keywords (para palavras-chave), participants (para população), results (para resultados), abstract (para resumo) e study design (para tipo de estudo).

- No corpo de texto, cada secção em que este se subdivida deve começar no início de uma página. ${ }^{1}$
Apelamos a todos que leiam atentamente as normas antes de submeter os vossos artigos. À primeira vista podem parecer extensas mas verão que o detalhe só simplificará o trabalho ao orientar a sua redacção.

Convidamos também todos os leitores a partilhar com os demais aquilo que fazem, investigam e aprendem no vosso dia-a-dia. Quantas vezes não andamos todos a trabalhar arduamente no nosso cantinho mas nos esquecemos do passo seguinte: partilhar para que aquilo que deu tanto trabalho a poucos possa ser valorizado e rentabilizado ao tornar-se útil para muitos. Se todos o fizermos sairemos todos mais e mais bem (in)formados.

\section{REFERÊNCIAS BIBLIOGRÁFICAS:}

1. Conselho Editorial da Revista Portuguesa de Clínica Geral. Normas para apresentação de artigos à Revista Portuguesa de Clínica Geral. Rev Port Clin Geral 2010 Mai-Jun; 26 (3): 325-40.

2. BIREME. Descritores em ciências da saúde (DeCS). São Paulo: Centro Latino-Americano e do Caribe de Informação em Ciências da Saúde. Disponível em: http://decs.bvs.br [acedido em 03/04/2010].

3. US National Library Medicine. Medical Subject Headings. Bethesda: National Library Medicine. Disponível em: http://www.nlm.nih.gov/mesh/ 2010/mesh_browser/MBrowser.html [acedido em 03/04/2010].

4. Patrias, K. Citing medicine: the NLM style guide for authors, editors, and publishers. 2nd ed. Bethesda (MD): National Library of Medicine (US); 2007. Disponível em: http://www.ncbi.nlm.nih.gov/bookshelf/ br.fcgi?book=citmed [acedido em 03/04/2010].

\section{CONFLITOS DE INTERESSE}

A autora declara não possuir conflitos de interesses. 